\title{
How medical education can contribute towards the reduction of maternal mortality in Angola: the teaching/learning process of Gynecology and Obstetrics
}

\author{
Mendes, M. ${ }^{1}$, Barbosa, J. ${ }^{2}$, Loureiro, E. ${ }^{3}$ Ferreira, M.A. ${ }^{4}$
}

1. Department of Education and Research of Gynecology and Obstetrics, Faculty of Medicine of the University Agostinho Neto Av. Hoji ya Henda, 116, Luanda, Angola. E-mail: manuelamendes@hotmail.com

2. Center for Medical Education, Faculty of Medicine of the University of Porto Al. Prof. Hernâni Monteiro, 4200-319 Porto, Portugal

3. Elizabete Maria Ferraz Loureiro Carteado Center for Medical Education, Faculty of Medicine of the University of Porto Al. Prof. Hernâni Monteiro, 4200-319 Porto, Portugal

4. Maria Amélia Duarte Ferreira Center for Medical Education, Faculty of Medicine of the University of Porto Al. Prof. Hernâni Monteiro, 4200-319 Porto, Portugal

\begin{abstract}
Background: In Angola the maternal mortality ratio is among the highest in the world. Medical students are an important target for intervention.

Objectives: To evaluate how students perceive the curricular unit of Gynecology and Obstetrics (G\&O) in a public institution of reference in Angola.

Methods: The study involved a sample of 147 students of the faculty of Medicine of the University Agostinho Neto, Luanda, Angola, attending the curricular unit of G\&O in the 5th and 6th years of the medical course. Data were obtained through surveys of opinion. The information of the scales was summarized through the construction of scores from the original items using the Principal Components Analysis.

Results: Students evaluated positively the curricular unit although emphasizing the lack of human and physical resources. The 5th year scored with higher values Teacher Performance and 6th year Students' Performance. Both years considered to have insufficient skills to meet the learning objectives.

Conclusion: Constraints were identified in the outcomes of the teaching/learning program. Several points emerged as crucial from this study: widespread the areas of teaching/learning, increase the number and quality of teaching staff, improve the monitoring of students and provide adequate infrastructures and medical equipment to support the teaching/learning program.
\end{abstract}

Keywords: Maternal Mortality, Obstetrics and Gynecology, Medical Education. African Health Sciences 2014;14(1): 228-236 http://dx.doi.org/10.4314/ahs.v14i1.36

\section{Introduction}

Globally, maternal mortality remains a major challenge to health systems, but is of particularly concern in developing countries. Taking the Millennium Declaration $^{1}$ as a reference, maternal mortality ratio (MMR) should be reduced by three-quarters from 1990 to $2015^{1}$. Despite the decline observed over the last 20 years, maternal mortality remains a major burden in many developing countries, and continues to account

\section{Correspondence author: \\ Maria Manuela Mendes \\ Department of Education and Research of Gynecology and Obstetrics, Faculty of Medicine of the University Agostinho Neto Av. Hoji ya Henda, 116, Luanda, Angola E-mail:manuelamendes@hotmail.com}

for $99 \%$ (355 000) of the maternal deaths ${ }^{2}$.

Despites the success of the current efforts to reduce the high MMR, they still need to be scaled up in order to overcome the present situation.

In Angola, MMR is considered to be among the highest in the world ${ }^{3}$. Poor access to health services in general, mainly because of the limited territorial coverage of the health facilities, and the lack of trained personnel are major concerns ${ }^{4,5}$. Only $22.5 \%$ of deliveries in Angola are carried out in health institutions, clearly indicating that most women have no skilled assistance at birth ${ }^{4}$. The high mortality around delivery is mostly due to causes that could be prevented, (such as bleeding, infections and hypertensive disorders), if these women had access to qualified professional assistance throughout pregnancy, at birth and immediately after it, to timely referred for emergency care ${ }^{6,7}$ 
The proportion of births attended by skilled health personnel is an important indicator for monitoring the Millennium Development Goal (MDG) of improving maternal health ${ }^{8}$. The medical school is a privileged area for intervention. Adequate and rapid competency oriented medical education is critical to prepare health professionals for effective obstetric interventions and live saving. ${ }^{9}$ In this context, the Angolan society needs urgent changes to create a new professional profile ${ }^{4,10}$.

The Faculty of Medicine of the University Agostinho Neto (FMUAN) is the oldest public institution responsible for the education of physicians in Angola. Over the past years, it has made a great effort to start a curricular reform ${ }^{11-13}$, coping with the mote updated references in medical education, to provide the new professionals with clinical competences to respond to the major health problems in the population ${ }^{14}$.

Therefore, given the great responsibility of medical schools in the training of medical students, this work aims to evaluate the students' point of view regarding (i) the teaching/learning process of G\&O in FMUAN and, (ii) the specific skills to match the learning objectives of the curricular unit.

\section{Methods}

The curricular unit of $G \& O$ runs throughout the academic year and takes place on the 5 th and 6 th years of the course of medicine at the FMUAN. In the 5 th year a workload of 271 hours is allocated to the curricular unit, 60 hours for lectures and 211 for theoretical - practical sessions. In 6th year, students are placed in medical teams in a ten weeks rotation schedule, in a paradigm of clinical practice. All students attending the 5th and 6th years of the Medicine Course at FMUAN were invited to participate in this cross-sectional study. Among the 196 eligible students, $81(82.7 \%)$ of 5 th year and 66 $(67.3 \%)$ of 6 th year have participated in this study.

The data collected are a sample obtained through surveys of opinion. The questionnaire comprised three sections. The first section included demographic characteristics. The second section included an evaluation scale for the curricular unit through 25 items using a 5 point Likert scale. The third section included a scale of the specific skills necessary to achieve the learning objectives of the curricular unit through 30 items in a 7 point Likert scale.

Additional questions were asked to further assess students' opinions.

The information of the scales was summarized through the construction of scores from the original items using the Principal Components Analysis. The Scree Plot criterion was used to determine the number of components ${ }^{15}$. It was considered that items with absolute factor loadings of 0.35 or greater were interpreted as being a meaningful part on the whole domain. The internal consistency was assessed by Cronbach's Alpha ${ }^{16}$. The score of each domain was described by median and percentiles 25 and 75 (p25 and p75), the highest value scores representing the higher levels. The Mann-Whitney test was used to compare the scores within each domain between academic years (5th and 6th). Cases with missing scores (7 students) were omitted from the analysis.

All statistics analyses were performed with the Predictive Analytics Software version 18.0 (PASW Statistics Software). The significance level was set at 0.05.

The ethical principles to accomplish this research followed the guidelines approved by Faculty of Medicine of the University of Porto and FMUAN. No identifying information was collected and subject participation was voluntary.

\section{Results \\ Characteristics of Population}

In the Course of Medicine of FMUAN, 54.2\%of the students were over 30 years old, $66.9 \%$ were females and $59.0 \%$ were working. Of note, a high prevalence of students were displaced from home (37.0\%) (Table 1).

\section{Dimensions and Internal Consistency of the Questionnaire}

The Scree Plot of the original scale "Evaluation of the curricular unit of G\&O" suggested the existence of three components explaining $38.5 \%$ of the variance.

A PCA followed by Varimax rotation was carried out. Component 1 was composed of 10 items expressing questions regarding methodology of the curricular unit and performance of the teaching staff. Therefore, it was decided to consider in its analysis two domains designated as Methodology of the Curricular unit $(\alpha=0.626)$ and Teachers' Performance $(\alpha=0.664)$. The PCA has identified in a second component items regarding Assessment $(\alpha=0.758)$. The item "assessment places too much emphasis on practice" was excluded through internal consistence 
analysis. The third component was the self-perceived Students' Performance $(\alpha=0.670)$. The items “assessment places too much emphasis on theoretical" and "volume of work affects my academic achievement" were excluded from this domain through internal consistency analysis (Table 2).

Table 1. Characteristics of students (5th and 6th years) of the Course of Medicine of FMUAN

\begin{tabular}{|c|c|}
\hline & $\mathbf{N}(\%)$ \\
\hline \multicolumn{2}{|c|}{ Age $(\mathrm{N}=144)$} \\
\hline$\leq 25$ & $19(13.2)$ \\
\hline ]25-30] & $47(32.6)$ \\
\hline ]30-56] & $78(54.2)$ \\
\hline \multicolumn{2}{|c|}{ Gender $(\mathrm{N}=142)$} \\
\hline Female & $95(66.9)$ \\
\hline Male & $47(33.1)$ \\
\hline \multicolumn{2}{|c|}{ Marital Status $(\mathrm{N}=147)$} \\
\hline Single & $94(63.9)$ \\
\hline Married & $50(34.0)$ \\
\hline Divorced & $2(1.4)$ \\
\hline Widower & $1(0.7)$ \\
\hline \multicolumn{2}{|c|}{ Worker $(\mathrm{N}=139)$} \\
\hline No & $57(41.0)$ \\
\hline Yes & $82(59.0)$ \\
\hline \multicolumn{2}{|c|}{ Displaced from home $(\mathrm{N}=135)$} \\
\hline No & $85(63,0)$ \\
\hline Yes & $50(37.0)$ \\
\hline
\end{tabular}


Table 2. Principal Components Matrix of the Scale "Evaluation of the Discipline of Gynecology and Obstetrics"

\begin{tabular}{|c|c|c|c|}
\hline & \multicolumn{3}{|c|}{ Component } \\
\hline & 1 & 2 & 3 \\
\hline Clearly defined objectives & 0.555 & & \\
\hline Adequate methods of teaching / learning & 0.467 & & \\
\hline Adequate bibliography & 0.361 & & \\
\hline My previous knowledge is sufficient to attend the discipline & & & 0.351 \\
\hline I prepare in advance for the activities & & & 0.573 \\
\hline I participate in the activities & & & 0.350 \\
\hline I use the recommended bibliography for further study in this discipline & & & 0.480 \\
\hline I am on time and assiduous & & & 0.491 \\
\hline I try to regularly clarify doubts with the teachers & & & 0.696 \\
\hline Workload affects my academic achievement & & & -0.481 \\
\hline The teaching team shows interest and enthusiasm in teaching & 0.421 & & \\
\hline The teaching team is scientifically updated & 0.571 & & \\
\hline The teaching team is pedagogically prepared & 0.480 & & \\
\hline The teaching team motivate students to think for themselves & 0.614 & & \\
\hline The teaching team is available to clarify any doubts & 0.519 & & \\
\hline The teaching team is punctual and assiduous & 0.411 & & \\
\hline The assessment system was set at the beginning of the discipline & 0.631 & & \\
\hline The assessment system was clearly defined & 0.400 & & \\
\hline The assessment method is adequate to the nature of this discipline & 0.550 & & \\
\hline Assessment places too much emphasis on theoretical knowledge & & & 0.444 \\
\hline Assessment places too much emphasis on practice & & -0.443 & \\
\hline The time at which assessment takes place is appropriate & & 0.592 & \\
\hline Subjects covered by assessment were clearly defined & & 0.732 & \\
\hline Subjects covered by assessment were discussed in the Discipline & & 0.751 & \\
\hline My study was adequate for carrying out the assessment tests & & 0.771 & \\
\hline Variance $($ Total $=35.8 \%)$ & $18.3 \%$ & $10.1 \%$ & $7.4 \%$ \\
\hline Eigenvalues & 4.8 & 2.6 & 1.9 \\
\hline
\end{tabular}

The Scree Plot of the original scale "Learning Objectives in the curricular unit of G\&O" suggested the existence of two components explaining $60.8 \%$ of the variance.
The first component was designated as Core Aims $(\alpha=0.968)$ and the second as Special Exams $(\alpha=0.890)$ (Table 3). 


\begin{tabular}{|c|c|c|}
\hline & \multicolumn{2}{|c|}{ Component } \\
\hline & 1 & 2 \\
\hline Perform obstetric medical history & 0.912 & \\
\hline Recommend pregnant women about appropriate life styles & 0.797 & \\
\hline $\begin{array}{l}\text { Recognize the complementary exams to apply for and at what stage in pregnancy should be } \\
\text { ordered }\end{array}$ & 0.737 & \\
\hline Be able to analyze the results of these exams and decide what to do & 0.831 & \\
\hline Identify and solve common problems that occur during pregnancy and puerperium & 0.791 & \\
\hline Perform preconception and prenatal query & 0.585 & \\
\hline Perform ultrasound & & 0.826 \\
\hline Perform hysterosalpingography & & 0.884 \\
\hline Perform colposcopy & & 0.875 \\
\hline Perform hysteroscopy & & 0.854 \\
\hline Perform cardiotocography & & 0.535 \\
\hline Perform a speculum examination & 0.720 & \\
\hline Perform fetal auscultation & 0.786 & \\
\hline Perform Leopold maneuver & 0.541 & \\
\hline Perform urine test strips & 0.380 & \\
\hline Perform cytology collect & 0.561 & \\
\hline Perform breast exam & 0.479 & \\
\hline Perform a pregnancy test & 0.627 & \\
\hline Complete registers and obstetric prenatal forms & 0.664 & \\
\hline Referencing pregnancy in the national health system & 0.705 & \\
\hline Understanding issues of reproductive physiology & 0.652 & \\
\hline Identify methods of contraception & 0.795 & \\
\hline Perform family planning & 0.817 & \\
\hline Identifying risk factors for genital and breast cancer & 0.674 & \\
\hline Dealing with problems of menopause & 0.796 & \\
\hline Detect gynecological infections & 0.757 & \\
\hline Identify reproductive pathology & 0.820 & \\
\hline Identify maternal fetal pathology & 0.900 & \\
\hline Identify cancer pathology & 0.931 & \\
\hline Attend child-birth & 0.911 & \\
\hline Variance $($ Total $=60.8 \%)$ & $52.4 \%$ & $8.5 \%$ \\
\hline Eigenvalues & 15.7 & 2.6 \\
\hline
\end{tabular}

\section{Evaluation of the Curricular unit of $\mathrm{G} \& \mathrm{O}$}

The students' perceptions were significantly different between the two academic years in the domains Assessment $(\mathrm{p}=0.003)$ and Students' Performance $(\mathrm{p}<0.001)$.
While the 6th year students scored highly in these two domains, the 5th year students scored higher in the Teacher Performance (Figure 1). 


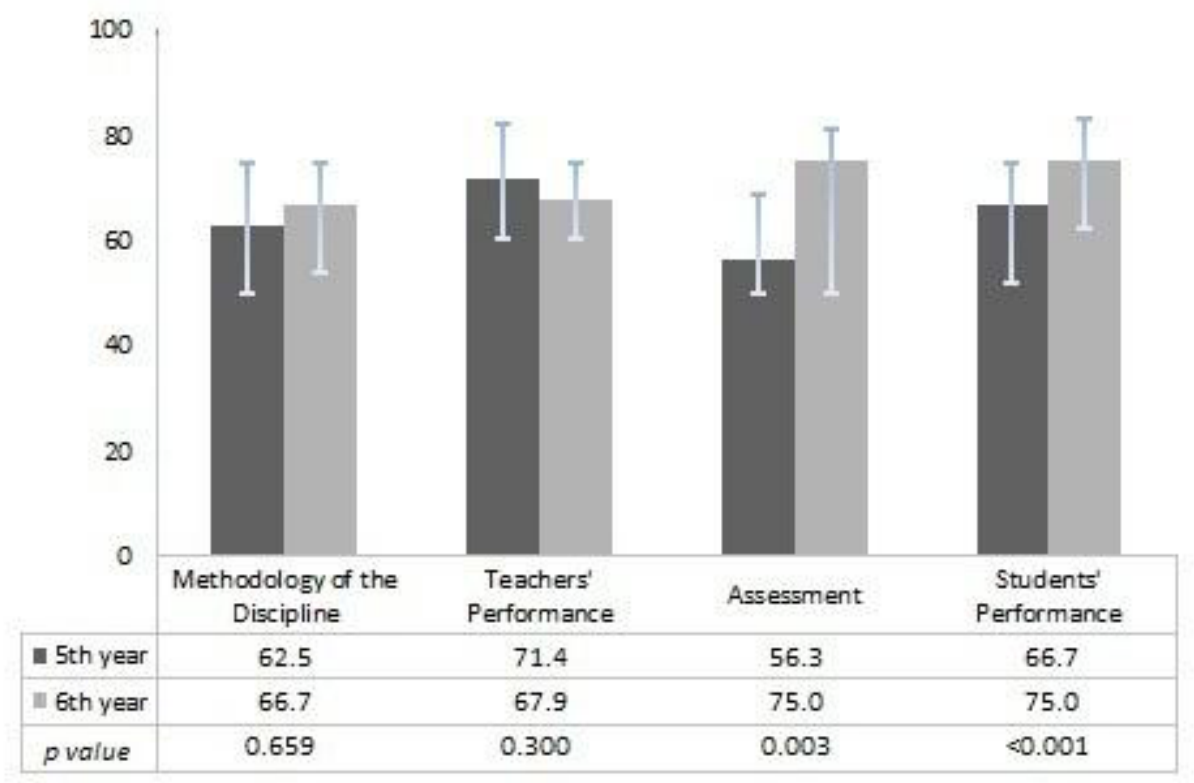

Learning objectives in the curricular unit of $\mathrm{G} \& \mathrm{O}$

The domain Core Aims was rated significantly different by academic years $(p<0.001)$ with acquisition of higher skills in the 6 th year (5th year $=41.3$ vs. 6 th year $=71.3$ ).
Students of the 5th year evaluate both domains negatively. For Special Exams, it was considered a very low level of competences acquired (16.7 points) (Figure 2).

Figure 2

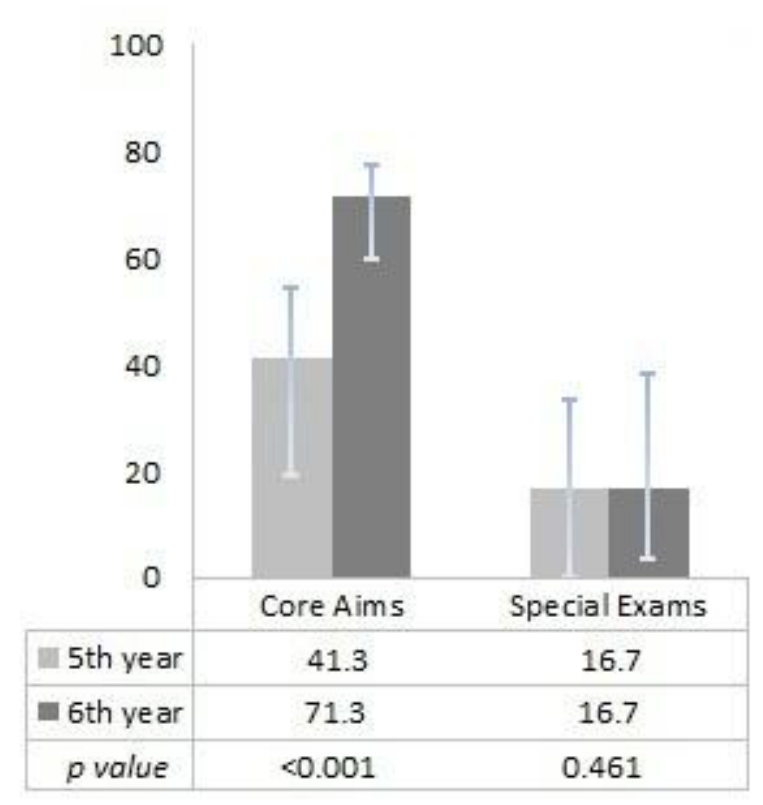


Suggested improvements to the curricular unit

Concerning the major changes to be introduced in the curricular unit of $\mathrm{G} \& \mathrm{O}, 49.1 \%$ reported the need to increase the number of practical classes, $32.0 \%$ of students recommended an enhancement of the teachers monitoring performance, and $8.9 \%$ of the students mentioned the introduction of new technologies for teaching/learning (Table 4).

Table 4. Improvements in Gynecology and Obstetrics

\begin{tabular}{lc}
\hline & $\mathbf{N}(\mathbf{\%})$ \\
\hline Increase the number of practical lessons & $55(49.1)$ \\
More monitoring from teachers & $36(32.1)$ \\
Introduction of new technologies & $10(8.9)$ \\
Provision of literatute & $9(8.1)$ \\
Classes only in working days & $2(1.8)$ \\
\hline Total & $112(100.0)$ \\
\hline
\end{tabular}

\section{Discussion}

Progress towards the MDG targets has been unequal in Africa ${ }^{17}$. This launches major challenges to countries in order to fulfill the international commitments. An issue to take into account is certainly the training of competent and health staff committed to the communities where they will develop their activities ${ }^{18}$. Unfortunately, the quality of higher-education courses in African countries is rarely assessed ${ }^{19}$. Further studies are needed in Africa, to clearly define the needs of trainee physicians and appropriate methods for health care management training throughout the continuum of health professional education ${ }^{20}$. The analysis of how students perceive the teaching/learning program in the training of health professionals, can contribute to improve teaching performance and curriculum reform, validating strategies for intervention.

The present study aimed to evaluate the teaching/ learning cross-talk within the curricular unit of $G \& O$ from the students' point of view.

As a result, four domains emerged in the "Evaluation of the curricular unit of G\&O": Methodology of the Curricular Unit, Teachers' Performance, Students' Performance and Assessment.

In a comprehensive way, the students evaluated positively the curricular unit. At the level of Students' Performance evaluation, the opinions differed between academic years, as the, 6th year rated its performance higher than the 5 th year. This is not surprising since 6 th year students are in the final year of the Course. However, despite the positive scores, neither the 5 th nor the 6th year students considered having a very high performance. Regarding the domain Assessment, students of 5th year considered it less adequate then 6th year. Of note, in 5 th year the assessment method is based only in multiple-choice tests, while in the 6th year a file form is used to quantify the students' performance (portfolios). Since assessment plays an integral role in helping physicians identifying and responding to their own learning needs ${ }^{21}$, there is a urge for the introduction of new methodologies to assess the medical competence. For example, the use of standardized patients to teaching and evaluate the technical and communication skills ${ }^{22}$. Likewise, objective and structured clinical examinations would facilitate a standard evaluation of performance and behaviors in medical care ${ }^{23}$.

The positive evaluation of Teachers Performance showed that, despite the limitations concerning the quality of educational available resources, the faculty has not spared efforts to keep the functionality of the structure. The motivation of teachers is not dependent on their benefits or the conditions of teaching, but on their level of responsibility ${ }^{24}$.

The analysis of the "Evaluation of Learning Objectives for the G\&O Curricular Unit" revealed that students identified two main domains of learning objectives, which were grouped in Core Aims and Special Exams. Regarding learning objectives there are two points to be highlighted. Firstly, although as expected 5th year students evaluated Core Aims lower than the 6th year, this evaluation was negative. Here, we must take account that students of 6th year have already gone through experiences in G\&O that the students of 5th year did not. 
However, the low classification given by the 5 th year students to the core aims that were taught in the first 2 weeks of the course, such as to perform speculum examination, Leopold maneuvers and to hear the fetal heart rate is an important concern. This point towards the need for the adoption and application of different methodologies of teaching/learning in order to lead the student to develop mechanisms of integration and recovery of the information learned in different curricular units.

Secondly, we must point out the low values assigned to the acquisition of competences by both academic years in goals that fit the Special Exams with no differences between them. This reflects the difficulties that the institution faces when organizing activities for teaching/ learning in areas where inadequate infrastructures and lack of resources were identified. Most African universities suffer from the effects of scarce financial resources. The lack of basic resources for teaching, the absence of simple laboratory equipment and supplies either for research or teaching, and, in some countries, long delays in salary payments are just some of the common problems faced by many African Institutions ${ }^{25}$.

Regarding the students' comments concerning the curricular unit of G\&O it was evidenced that students feel the need to increase the number of practical lessons, greater and better monitoring of teaching, and improved integration of new technologies in the teaching/ learning programs. This fact is of great concern for the Department of Education and Research (DER) of G\&O since, in recent years, the course has become increasingly theoretical due to the increasing number of students, the nonexistence of wards where they can have practical lessons, as well as the lack of teachers and teaching-learning resources. The urge to reverse this situation and provide clinical opportunities by training academic staff, is an important challenge. However, presently, this is not possible at FMUAN, since there is a great dispersion of the teaching staff. In addition the training of new teachers and differentiation of those on duty has not been possible despite the efforts developed.

This article describes our efforts to identify the student perceptions on the teaching/learning curriculum of $\mathrm{G} \& \mathrm{O}$, in order to advance towards its improvement according to local needs. Assessing the students was important for granting effectiveness in achieving this goal. Professionals trained, motivated and efficient are the key to delivery and management of care ${ }^{23}$.

\section{Limitations of the study}

Regardless the importance of the results obtained, the self-evaluation is neither objective nor free from the beliefs and values that the individuals hold about themselves ${ }^{26}$. Despite knowing what the student thinks he is capable of, we cannot provide data for the real performance ${ }^{27}$.

\section{Conclusion}

This study provides some useful insights into the preparedness of medical students in the area of G\&O. In a comprehensive way, the students evaluated positively the curricular unit although underlying the lack of human and physical resources. Some weaknesses were demonstrated in the acquisition of specific skills to meet the learning objectives. In striving to achieve international targets such as the Millennium Development Goals, the investment in the education of health professionals has to be a top priority for Angola.

\section{Acknowledgments}

This work was supported by the European Commission and the Calouste Gulbenkian Foundation under Project EDULINK "A NAME for Health - A Network Approach in Medical Education for the Pursuit of Quality of Higher Education Institutions and Health Systems" (Grant contract number: 9-ACPRPR-18\#29) and the Portuguese Institute for Development Support (IPAD) under the project "Structuring Program of Quality and Excellence of Education/Medical Training in FMUAN: Action for the Promotion of Health of Populations in Angola".

\section{References}

1. United Nations. United Nations Millennium Declaration. UN New York; 2000.

2. World Health Organization. Trends in Maternal Mortality: 1990 to 2008. Estimates developed by WHO, UNICEF, UNFPA and The World Bank. Geneva http:// whqlibdoc who int/publications/2010/9789241500265_ eng pdf [accessed on June 2012]. 2010.

3. Pettersson KO, Christensson K, de Freitas EGG, Johansson E. Adaptation of health care seeking behavior during childbirth: Focus group discussions with women living in the suburban areas of Luanda, Angola. Health Care for Women International. 2004; 25(3): 255-80.

4. Government of Angola and UNDP. Angola Millennium Development Goals Progress Report: Government of Angola and UNDP; 2005. 
5. Ajenifuja K, Adepiti C, Ogunniyi S. Post partum haemorrhage in a teaching hospital in Nigeria: a 5-year experience. African Health Sciences. 2010; 10(1).

6. Campbell OMR, Graham WJ. Strategies for reducing maternal mortality: getting on with what works. The Lancet. 2006; 368(9543): 1284-99.

7. Bates I, Chapotera G, McKew S, Van Den Broek N. Maternal mortality in sub $\square$ Saharan Africa: the contribution of ineffective blood transfusion services. BJOG: An International Journal of Obstetrics \& Gynaecology. 2008; 115(11): 1331-9.

8. Makoka D. Towards an understanding of regional disparities in social inequities in maternal health in Malawi. African Health Sciences. 2010; 9(4).

9. Homaifar N, Mwesigye D, Tchwenko S, Worjoloh A, Joharifard S, Kyamanywa P, et al. Emergency obstetrics knowledge and practical skills retention among medical students in Rwanda following a short training course. International Journal of Gynecology \& Obstetrics. 2012.

10. Faculdade de Medicina da Universidade Agostinho Neto. Perfil do Médico em Angola: Universidade do Porto; 2009.

11. Faculdade de Medicina da Universidade Agostinho Neto. Avaliação Interna - Segundo os Standards Globais da Federação Mundial de Educação Médica. Revista Angolana de Educação Médica. 2006.

12. Faculdade de Medicina da Universidade Agostinho Neto. Relatório de Auto-Avaliação do Curso Medicina Programa de cooperação entre a Faculdade de Medicina da Universidade do Porto (FMUP) e a Faculdade de Medicina da Universidade Agostinho Neto (FMUAN). 2007.

13. Ferreira A. Princípios gerais da reforma curricular na Faculdade de Medicina da UAN; Deliberação do Conselho Científico. Revista Angolana de Educação Médica. 2003: 27-31.

14. Fresta M. Reforma do Ensino Médico Público em Angola - O QUÊ? Para QUÊ e COMO? . Revista Angolana de Educação Médica. 2003; No 0 - ano 1.

15. Tabachnick BG, Fidell LS, Osterlind SJ. Using multivariate statistics. 2001.

16. Bland JM, Altman DG. Statistics notes: Cronbach's alpha. Bmj. 1997; 314(7080): 572.

17. Kebede D, Soumbey-Alley W, Asamoah-Odei E, Lusamba-Dikassa P, Sambo L. Progress on the healthrelated MDGs in the African Region. African Health Monitor. 2010; 10: 10-7.

18. Education TFoH, Society. Higher education in developing countries: peril and promise: World Bank; 2000.

19. Helen N, Sue P, Imelda B. Development of a quality assurance handbook to improve educational courses in Africa. Human Resources for Health. 2008; 6.

20. Busari JO, Berkenbosch L, Brouns JW. Physicians as managers of health care delivery and the implications for postgraduate medical training: a literature review. Teaching and Learning in Medicine. 2011; 23(2): 18696.

21. Cox M, Irby DM, Epstein RM. Assessment in medical education. New England Journal of Medicine. 2007; 356(4): 387-96.

22. Ravitz P, Lancee WJ, Lawson A, Maunder R, Hunter JJ, Leszcz M, et al. Improving Physician-Patient Communication Through Coaching of Simulated Encounters. Academic Psychiatry. 2013; 37(2): 87-93.

23. Serour GI. Healthcare workers and the brain drain. International Journal of Gynecology \& Obstetrics. 2009; 106(2): 175-8.

24. Chickering AW, Gamson ZF, Poulsen SJ. Seven principles for good practice in undergraduate education. Racine, WI: The Johnson Foundation, Inc,. 1987.

25. Teferra D, Altbachl PG. African higher education: Challenges for the 21st century. Higher Education. 2004; 47(1): 21-50.

26. Barbosa J, Severo M, Fresta M, Ismail M, Ferreira MA, Barros H. How students perceive medical competences: a cross-cultural study between the Medical Course in Portugal and African Portuguese Speaking Countries. BMC Medical Education. 2011; 11(1): 2430.

27. Stewart J, O'Halloran C, Barton JR, Singleton SJ, Harrigan P, Spencer J. Clarifying the concepts of confidence and competence to produce appropriate selfevaluation measurement scales. Medical Education. 2000; 34(11): 903-9. 